\title{
BMJ Open Obesity-related behaviours and BMI in five urban regions across Europe: sampling design and results from the SPOTLIGHT cross-sectional survey
}

Jeroen Lakerveld, ${ }^{1}$ Maher Ben Rebah, ${ }^{2}$ Joreintje D Mackenbach, ${ }^{1}$
Hélène Charreire, ${ }^{2,3}$ Sofie Compernolle, ${ }^{4}$ Ketevan Glonti, ${ }^{5}$ Helga Bardos, ${ }^{6}$
Harry Rutter, ${ }^{5}$ Ilse De Bourdeaudhuij, ${ }^{4}$ Johannes Brug,,${ }^{2}$ Jean-Michel Oppert ${ }^{2,7}$

\section{ABSTRACT}

To cite: Lakerveld J, Ben Rebah M, Mackenbach JD, et al. Obesity-related behaviours and BMI in five urban regions across Europe: sampling design and results from the SPOTLIGHT crosssectional survey. BMJ Open 2015;5: 008505 .

doi:10.1136/bmjopen-2015008505

- Prepublication history for this paper is available online. To view these files please visit the journal online (http://dx.doi.org/10.1136/ bmjopen-2015-008505).

$\mathrm{JL}$ and MBR contributed equally.

Received 15 April 2015 Revised 3 July 2015 Accepted 4 August 2015

CrossMark

For numbered affiliations see end of article.

Correspondence to Dr Jeroen Lakerveld; j.lakerveld@vumc.nl Europe. area density. survey.
Objectives: To describe the design, methods and first results of a survey on obesity-related behaviours and body mass index (BMI) in adults living in neighbourhoods from five urban regions across

Design: A cross-sectional observational study in the framework of an European Union-funded project on obesogenic environments (SPOTLIGHT).

Setting: 60 urban neighbourhoods (12 per country) were randomly selected in large urban zones in Belgium, France, Hungary, the Netherlands and the UK, based on high or low values for median household income (socioeconomic status, SES) and residential

Participants: A total of 6037 adults (mean age 52 years, $56 \%$ female) participated in the online

Outcome measures: Self-reported physical activity, sedentary behaviours, dietary habits and BMI. Other measures included general health; barriers and motivations for a healthy lifestyle, perceived social and physical environmental characteristics; the availability of transport modes and their use to specific destinations; self-defined neighbourhood boundaries and items related to residential selection.

Results: Across five countries, residents from low-SES neighbourhoods ate less fruit and vegetables, drank more sugary drinks and had a consistently higher BMI. SES differences in sedentary behaviours were observed in France, with residents from higher SES neighbourhoods reporting to sit more. Residents from low-density neighbourhoods were less physically active than those from high-density neighbourhoods; during leisure time and (most pronounced) for transport (except for Belgium). BMI differences by residential density were inconsistent across all countries.

Conclusions: The SPOTLIGHT survey provides an original approach for investigating relations between environmental characteristics, obesity-related behaviours and obesity in Europe. First descriptive results indicate considerable differences in health behaviours and BMI between countries and neighbourhood types.

\section{Strengths and limitations of this study}

- We used harmonised data across Europe to characterise neighbourhoods in terms of socioeconomics and residential area density.

- The large sample size allowed comparisons between neighbourhood types and countries.

- The sampling strategy and survey results may yield several insights for public health researchers and policymakers in the European context.

- The low response rate may indicate selective inclusion of participants.

- Self-reported outcomes may be biased due to social desirability bias or recall bias.

\section{INTRODUCTION}

Poor diets, lack of physical activity and sedentary behaviour are major drivers of a wide range of non-communicable diseases including obesity. ${ }^{1-3}$ Such 'obesity-related behaviours' are influenced by contextual factors, next to individual factors. ${ }^{4}$ For instance, physical activity can be affected by the availability of opportunities and equipment, interconnectivity of streets or proximity of parks, ${ }^{56}$ and dietary habits by the availability, accessibility and affordability of food outlets and food items. ${ }^{78}$ It may be that some aspects of the environment are more 'obesogenic' than others as they contain elements that are more likely to promote obesity-related behaviours and weight gain in individuals or populations. ${ }^{9}$

The 'obesogenicity' of environments is likely to be unevenly distributed across neighbourhoods and countries. A social gradient in obesity-related behaviours and obesity prevalence has been recognised in developed economies, with increased obesity rates in socioeconomically disadvantaged neighbourhoods. ${ }^{8}$ Indicators of socioeconomic status 
(SES), such as the neighbourhood median income level, median educational level or residential property value, have been found to be inversely associated with obesity. ${ }^{10}$

In contrast to documentation of socioeconomic drivers of obesity, current evidence on potentially obesogenic factors from our physical environment remains inconsistent, as recently reviewed. ${ }^{5}{ }^{611-14}$ Among a large range of physical environmental characteristics studied, only two built environmental factors appear to be consistently associated with weight status: urban sprawl which is positively associated with obesity, and land use mix which is negatively associated. ${ }^{6}{ }^{13}$ Both land use mix and urban sprawl are synthetic indicators based on a set of characteristics such as residential area density (RAD, commonly defined as the measure of housing density expressed as dwellings or lots per hectare). Many of the built environment characteristics described coexist in urban areas. High-RAD places are often well connected, with destinations close by, and have good infrastructure for walking, cycling and public transport. ${ }^{5}$ Currently, there is a lack of comparative studies that address such potentially important neighbourhood characteristics in relation to health behaviours and health outcomes. ${ }^{15}$ In addition, most studies relating urban density measures to obesity and its associated behaviours were conducted in North America, and the extent to which they are generalisable to Europe is unclear, given the large differences in built environments between European and North American cities. ${ }^{6}$

This paper has two main aims: (1) to describe the design and methods of a survey on obesity-related behaviours and weight status in adults living in urban regions in Belgium, France, Hungary, the Netherlands and the UK and (2) to provide descriptive data on differences in obesity-related behaviours and body mass index (BMI) between high-SES and low-SES and high-RAD and low-RAD neighbourhoods, across and within the five locations.

\section{METHODS}

Setting

This study is part of the European Union-funded SPOTLIGHT ('Sustainable prevention of obesity through integrated strategies') project for which the rationale, design, procedures and methodology have been published elsewhere. ${ }^{16}$ For the current study, research was conducted in five European countries: Belgium, France, Hungary, the Netherlands and the UK. Large cities in each of these countries were defined as study areas: Ghent and suburbs in Belgium; Paris and suburbs in France; Budapest and suburbs in Hungary; the Randstad (a conurbation including Amsterdam, Rotterdam, the Hague and Utrecht) in the Netherlands and Greater London in the UK. Characteristics of these study areas are presented in table 1. Neighbourhood level was defined according to small-scale local administrative boundaries as used in each country except for Hungary. Budapest is divided into districts and suburbs that are highly heterogeneous in terms of population and much larger than the equivalent administrative areas in the other study countries. In order to ensure comparability between study areas, we thus defined $1 \mathrm{~km}^{2}$ areas to represent neighbourhoods in Budapest and suburbs.

Across all five locations, the average area of a neighbourhood was $1.5 \mathrm{~km}^{2}$ and the mean population density was 2700 inhabitants per neighbourhood. Neighbourhoods in Ghent were the least populated and those in Paris were the smallest in size. Greater London had the largest neighbourhoods both in population and area size (table 1$)$.

\section{Neighbourhood sampling}

Sampling of neighbourhoods in the five countries was based on a combination of RAD and SES data at the neighbourhood level. Data on RAD were obtained from the Urban Atlas database. ${ }^{17}$ This Atlas is a geographic information system (GIS) database distributed by the European Environmental Agency, based on a compilation of satellite photographs covering Europe and providing high-resolution land use data. ${ }^{18}$ The Urban Atlas includes a land use index that is comparable across European countries. The index is based on the density of residential areas, commercial and industrial zones, green urban areas, commercial areas, industrial areas and water areas. RAD is calculated as the percentage of coverage of buildings devoted to residential facilities in a minimum mapping unit (MMU) of 0.5 ha. Among six existing residential density categories in the Urban Atlas, only two classes were used, defined as high and low RAD (corresponding to $>80 \%$ and $<50 \%$ of areas covered by residential buildings, respectively). Figure 1 illustrates the GIS process adapting the residential density variable from the MMU to the neighbourhood scale for the SPOTLIGHT study area in the UK.

Neighbourhood SES data were based on income data at the neighbourhood level retrieved from national statistical offices and national census databases. Two classes of SES were used (high and low, corresponding to the first and third tertiles of the distribution in each country; table 1). The combination of the neighbourhood SES and RAD categories allowed the definition of four classes: high SES/high RAD, low SES/high RAD, high SES/low RAD and low SES/low RAD. On the basis of this $2 \times 2$ grid applied to each study area in the five countries, three neighbourhoods were randomly sampled per neighbourhood category (ie, 12 neighbourhoods per country, 60 neighbourhoods in total). An additional inclusion criterion was that sampled neighbourhoods had to contain at least 800 households.

\section{Recruitment of individuals}

Adult residents from the selected neighbourhoods were invited to participate in an online survey. In the selected 
Table 1 Characteristics of the wider study areas in the five countries of the SPOTLIGHT survey

Neighbourhood characteristics according to each study area

\begin{tabular}{|c|c|c|c|c|c|c|}
\hline \multirow[b]{2}{*}{ Country } & \multirow[b]{2}{*}{ Study area } & \\
\hline & & Name & $\begin{array}{l}\text { Mean } \\
\text { population }\end{array}$ & $\begin{array}{l}\text { Mean } \\
\text { surface } \\
\left(\mathrm{km}^{2}\right)\end{array}$ & $\begin{array}{l}\text { First tertile of } \\
\text { income (in } €)^{*}\end{array}$ & $\begin{array}{l}\text { Third tertile of } \\
\text { income (in } €)^{\star}\end{array}$ \\
\hline Belgium $†$ & $\begin{array}{l}\text { Ghent and suburbs have around } 400000 \text { inhabitants and } \\
\text { cover } 537 \mathrm{~km}^{2} \text { (ie, } 464 \text { neighbourhoods) }\end{array}$ & Statistical sectors & 946 & 1.4 & $<22034$ & $\geq 24351$ \\
\hline France & $\begin{array}{l}\text { Paris and first suburbs have a population of over } 6 \text { million } \\
\text { inhabitants and cover } 762 \mathrm{~km}^{2} \text { (ie, } 2749 \text { neighbourhoods) }\end{array}$ & $\begin{array}{l}\text { Ilot Regroupé pour } \\
\text { l'Information Statistique } \\
\text { (IRIS) }\end{array}$ & 2411 & 0.3 & $<17290$ & $\geq 25236$ \\
\hline Hungary§ & $\begin{array}{l}\text { Budapest and the } 80 \text { settlements surrounding the capital city } \\
\text { have more than } 2.5 \text { million inhabitants and cover } 2538 \mathrm{~km}^{2} \\
\text { (ie, } 1689 \text { neighbourhoods) }\end{array}$ & $1 \mathrm{~km}^{2}$ grid using a GIS & 1817 & 1.0 & $\leq 3269$ & $\geq 3955$ \\
\hline $\begin{array}{l}\text { The } \\
\text { Netherlands** }\end{array}$ & $\begin{array}{l}\text { The Randstad (Amsterdam, Rotterdam, The Hague and } \\
\text { Utrecht) have a population of } 7.1 \text { million inhabitants and } \\
\text { cover } 3790 \mathrm{~km}^{2} \text { (ie, } 2078 \text { neighbourhoods) }\end{array}$ & Buurt & 2343 & 1.2 & $<29000$ & $\geq 32000$ \\
\hline UK†† & $\begin{array}{l}\text { Greater London (including the City of London and } 32 \text { London } \\
\text { boroughs) has a population of } 8.1 \text { million and covers } \\
1572 \mathrm{~km}^{2} \text { (ie, } 1649 \text { neighbourhoods) }\end{array}$ & MSOA & 5607 & 3.6 & $<46888$ & $\geq 55474$ \\
\hline
\end{tabular}


A Residential density at MMU scale (from European Urban Atlas database)

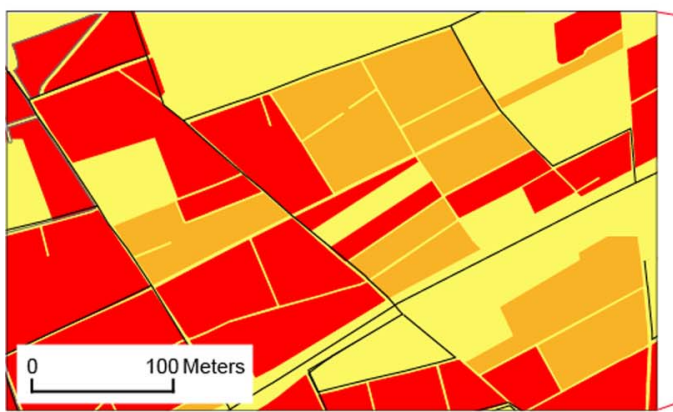

$\%$ of area covered by residential buildings

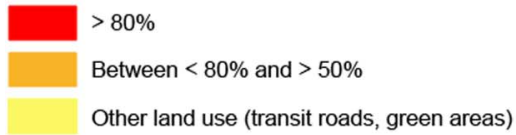

Level of residential density Urban characteristics

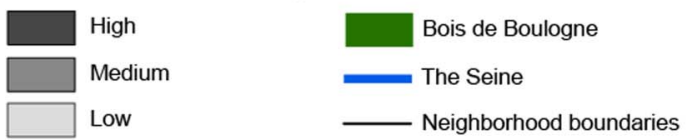

B

Residential density at neighborhood scale

(aggregation of level of residential density at MMU scale)

Figure 1 Example of urban residential density at different levels: minimum mapping unit (MMU) level (A) and neighbourhood level $(B)$ in Paris, France. (MMU, minimum mapping unit).

neighbourhoods, a random sample of residential addresses was drawn from postal companies (the Netherlands), Yellow Pages (France), electoral rolls (the UK) or public administration services (Belgium, Hungary). Since we expected lower response rates from participants in low-SES neighbourhoods, ${ }^{19}$ we oversampled adults from low-SES neighbourhoods (1200 adults per neighbourhood) relative to high-SES neighbourhoods (800 adults per neighbourhood). The aim was to recruit at least 100 participants per neighbourhood (6000 in total), with an anticipated response rate of around 10\%. Between February and September 2014, participants were recruited via postal invitation using the Dillman method. ${ }^{20}$ In order to increase response rates, a prize (one or more bicycles) was offered for participants in the Netherlands, Belgium and Hungary. Furthermore, we used posters, flyers and local newspaper advertisements to raise awareness about the survey. In the Netherlands and France, in the neighbourhoods with lowest response rates, researchers also randomly visited people at home to encourage study participation. Response rates per country and neighbourhood type are shown in table 2. A total of 6037 adults completed the survey.

All survey participants provided informed consent.

\section{Data collection}

Information on individual characteristics was obtained through the online survey. Participants were able to complete a paper-based survey instead of the online version on request. Details of the variables included in the survey are described below.

\section{Physical activity}

Information on leisure time physical activity and transport-related physical activity was collected with an adapted version of the International Physical Activity Questionnaire (IPAQ). The IPAQ has been validated in a 12 country study, with good reliability and acceptable criterion validity. ${ }^{21}$ The items about transport were divided into questions about mode of transport to work mode of transport for other destinations. Additionally, items inquiring about reasons for choosing modes of transport were included. Respondents were also asked about car and bicycle ownership, and whether they had a garden or yard, or access to an allotment or city garden.

\section{Sedentary behaviours}

For sedentary behaviours, we used questions developed and validated by Marshall $e t a l^{22}$ which assess time spent sitting on weekdays and weekend days: (1) travelling to and from places, (2) at work, (3) watching television, (4) using a computer or tablet at home and (5) for leisure, not including television viewing. We added 'using tablet' under point 4 because tablets are often used instead of computers nowadays. The Marshall questionnaire has been shown to be reliable for sitting time at work, watching television and using a computer at home during weekdays (repeatability coefficients $\mathrm{r}=0.84-0.78)$. Validity coefficients were previously shown to be highest for sitting time at work and using a computer at home $(\mathrm{r}=0.69-0.74)$. With the exception of computer use and watching television for women, validity of the weekend-day sitting time items has previously been shown to be low. ${ }^{22}$ Participants were also asked to 
Table 2 Invitation and response rates of the SPOTLIGHT survey

\begin{tabular}{|c|c|c|c|c|c|}
\hline & High SES/high RAD & Low SES/high RAD & High SES/low RAD & Low SES/low RAD & Total \\
\hline \multicolumn{6}{|l|}{ Belgium } \\
\hline Approached & 2400 & 3486 & 2400 & 3578 & 11864 \\
\hline Responded & 410 (17.1\%) & 451 (12.9\%) & 449 (18.7\%) & 464 (13.0\%) & $1849^{\star}(15.6 \%)$ \\
\hline \multicolumn{6}{|l|}{ France } \\
\hline Approached & 2911 & 2058 & 2196 & 1612 & 8777 \\
\hline Responded & $253(8.7 \%)$ & $183(8.9 \%)$ & 228 (10.4\%) & $156(9.7 \%)$ & $844 †(9.6 \%)$ \\
\hline \multicolumn{6}{|l|}{ Hungary } \\
\hline Approached & 2690 & 3490 & 2304 & 3359 & 11843 \\
\hline Responded & $163(6.1 \%)$ & $264(7.6 \%)$ & $188(8.2 \%)$ & $260(7.7 \%)$ & $875(7.4 \%)$ \\
\hline \multicolumn{6}{|l|}{ The Netherlands } \\
\hline Approached & 2336 & 3539 & 2382 & 3509 & 11766 \\
\hline Responded & 405 (17.3\%) & $318(9.0 \%)$ & 367 (15.4\%) & $519(14.8 \%)$ & 1609 (13.7\%) \\
\hline \multicolumn{6}{|l|}{ UK } \\
\hline Approached & 2303 & 3441 & 2354 & 3545 & 11643 \\
\hline Responded & $173(7.5 \%)$ & $203(5.9 \%)$ & 247 (10.5\%) & $225(6.3 \%)$ & $860(7.4 \%) \ddagger$ \\
\hline \multicolumn{6}{|l|}{ Total } \\
\hline Approached & 12640 & 16014 & 11636 & 15603 & 55893 \\
\hline Responded & $1404(11.1 \%)$ & $1419(8.9 \%)$ & $1479(12.7 \%)$ & $1624(10.4 \%)$ & $6037(10.8 \%)$ \\
\hline \multicolumn{6}{|c|}{$\begin{array}{l}\text { Residents with unknown neighbourhood type: } \\
{ }^{*} n=75 \text {, } \\
t n=24\end{array}$} \\
\hline
\end{tabular}

report on the numbers within the household of electronic screens (including desktop computers, laptops, televisions, tablets).

\section{Dietary habits}

We used a number of short items commonly used in food frequency questionnaires related to intakes of specific foods (fruit, vegetables, fish, fast food, sweets, sugary drinks and alcoholic beverages) instead of a full food frequency questionnaire. Options for answers were 'once a week or less', '2 times a week', ' 3 times a week', ' 4 times a week', '5 times a week', '6 times a week', '7 times a week (each day)', 'twice a day' and 'more than twice a day'. Additionally, we asked participants how often they ate breakfast, lunch and dinner (range: $<1-7$ times per week for each) and how many times a week they cooked a meal, as opposed to eating ready-to-eat or takeaway foods or meals (range: $<1-7$ times per week).

\section{General health and anthropometrics}

Participants were asked to report their height, weight, smoking behaviour (current, previous, never), hours of sleep on a usual night and happiness. We included a visual analogue scale to assess perception of general health, ranging from 0 (very unhealthy) to 100 (very healthy). Participants were asked to report if any longstanding illness, disability or infirmity limited their daily activities or work (yes/no).

\section{Barriers for healthy behaviours}

A selection of seven items from the Neighborhood Quality of Life Study (NQLS) ${ }^{23}$ was included to assess individual barriers to regular physical activity (eg, 'lack of interest in exercise or physical activity', 'lack of time', 'lack of equipment'). Barriers to healthy eating consisted of 10 items from the pan-European consumer attitudinal study and (eg, 'busy lifestyle' and 'price'). ${ }^{24}$

\section{Perceived physical environment}

Perceived physical environmental characteristics potentially related to physical activity were assessed using items based on the validated ALPHA questionnaire, ${ }^{25}$ supplemented with items regarding the food environment based on the Multi Ethnic Study of Atherosclerosis (MESA) survey. ${ }^{26}$ Furthermore, we added items asking about specific destinations (eg, food outlets, recreational areas), reasons for going (or not going) to these destinations and mode of transport for getting there.

\section{Social environment}

Aspects of neighbourhood social capital were measured using a 13-item scale (Cronbach's $\alpha=0.86$ ), with fivepoint ordinal scale answering categories ranging from 1 (totally disagree) to 5 (totally agree). Three factors identified in a previous study on the basis of a principal component analysis ${ }^{27}$ were confirmed in the present study, namely: 'social network' (Cronbach's $\alpha=0.83$ ), 'social cohesion' (Cronbach's $\alpha=0.79$ ) and 'feeling at home' (Cronbach's $\alpha=0.58$ ). Examples of items within these factors were 'most people in this neighbourhood can be trusted', 'I often visit my neighbours in their home' and 'If I get the chance, I will move away from this neighbourhood). Additionally, participants were asked 
whether most of their friends lived in their neighbourhood or not.

\section{Self-defined residential neighbourhood boundaries}

Respondents were provided with an online map showing the area around their residential address and were asked to draw the boundaries of what they regarded as their residential neighbourhood (online, using a self-mapping tool developed for this purpose, or on a printout when using a paper version of the questionnaire).

\section{Neighbourhood satisfaction/mobility intentions}

Respondents were asked to indicate which of the following five situations fitted best with their current housing situation: (I would like to: continue to live in my neighbourhood/move house to another neighbourhood and plan to do so soon/move house to another neighbourhood, but cannot for financial reasons/move house to another neighbourhood, but I cannot for other reasons (family, work, etc)/no specific wish about moving house). In addition, we asked for factors that might influence their decision to live in their current neighbourhood (cost of housing/distance to work or school/ there are restaurants or bars nearby/it is an attractive neighbourhood/there is easy access to transport facilities/it is easy to walk to shops and services (eg, bank, post office)/it is close to recreation facilities, parks or sports facilities/my friends/family live close by/other).

Respondents were also asked about the number of years they had lived in their neighbourhood and whether or not they spent most of their leisure time in their local neighbourhood.

\section{Sociodemographics}

Questions on age, gender, educational attainment, employment status, hours per week spent on work/ study, household composition and net household income per month or year were asked. To enable comparison of the country-specific education systems, we recoded educational attainment into 'higher' or 'lower'.

\section{Translation of the survey into target languages}

The questionnaire was translated from English to French, Hungarian, Flemish and Dutch according to published guidelines for the translation of measurement instruments. ${ }^{28}{ }^{29}$ We used forward and backward translations by researchers working in the same or similar field, and native speakers of English and the targeted languages. In each country, two independent experts translated the questionnaire into their language. Together with a third person, the two versions were combined into one. This combined version was translated back into English by two other experts. An expert committee (four translators together with researchers) reviewed all translations and reports and took decisions on discrepancies.

\section{Data analyses}

A standardised in-country data cleaning protocol was followed by each research centre involved. After merging in-country data sets, descriptive statistics and comparisons were performed centrally, using IBM SPSS Statistics V.22.0. Overall and country-specific values were calculated for minutes per day spent on moderate-to-vigorous physical activity (during leisure and for transport), total sitting time (minutes/day), weekly frequency of consumption of fruit, vegetables, fish, sugary drinks, sweets, fast food and BMI. Analysis of covariance was used to compare sex-adjusted and age-adjusted values between neighbourhood types (ie, high SES/high RAD, low SES/ high RAD, high SES/low RAD and low SES/low RAD). Differences between neighbourhood types were tested in post hoc analyses using Bonferroni correction for multiple comparisons (with log-transformed values in some analyses to stabilise the variance of residuals).

\section{RESULTS}

Table 3 describes the sociodemographic characteristics of the participants and descriptive statistics of their obesity-related behaviours and BMI. The mean age was 52 (SD 16.4) years and $56 \%$ were female.

Generally, across all countries, residents from low-SES neighbourhoods ate less fruit and vegetables, drank more sugary drinks and consistently had a higher BMI. Residents from low-RAD neighbourhoods were slightly less physically active than those from high-RAD neighbourhoods during leisure time and this difference was even more pronounced with regard to active transport use. Mean BMI values ranged around the overweight threshold, with lowest values reported in France (24.5 (SD 4.4)) and highest in Hungary (26.0 (SD5.1)).

Pronounced SES differences in sedentary behaviours were only observed in France, with those from higher SES neighbourhoods reporting sitting considerably more (about $1.5 \mathrm{~h} /$ day more) than those from low-SES neighbourhoods. The finding that residents from low-RAD neighbourhoods were less physically active than those from high-RAD neighbourhoods was true for all countries except for Belgium, where participants from low-SES/low-RAD neighbourhoods were more active for transport relative to other neighbourhood types. The highest levels of active transport (about an hour per day) were reported in low-SES/high-RAD neighbourhoods in the Netherlands. The largest RAD differences in active transport were seen in France and the UK, where people from high-RAD neighbourhoods who walked or cycled did so for approximately $15 \mathrm{~min}$ more per day than their counterparts in low-RAD areas. Highest values were measured in low-SES neighbourhoods in Hungary (26.6 kg/m ${ }^{2}$ across both RAD types) and low-SES/low-RAD neighbourhoods in the UK (mean 26.4). Differences in BMI by RAD were inconsistent across countries. 
Table 3 Demographic, anthropometric and behavioural characteristics of adults across countries and neighbourhood types

\begin{tabular}{|c|c|c|c|c|c|c|c|c|c|c|c|c|c|}
\hline $\begin{array}{l}\text { Neighbourhood } \\
\text { type }\end{array}$ & Age & $\begin{array}{l}\text { Gender } \\
\text { (female, \%) }\end{array}$ & $\begin{array}{l}\text { High } \\
\text { educational } \\
\text { level, \% }\end{array}$ & $\begin{array}{l}\text { Total } \\
\text { leisure time } \\
\text { MVPA (min/ } \\
\text { day) }\end{array}$ & $\begin{array}{l}\text { Total MVPA } \\
\text { for transport } \\
\text { (min/ day) }\end{array}$ & $\begin{array}{l}\text { Total sitting } \\
\text { time (min/day) }\end{array}$ & $\begin{array}{l}\text { Fruit } \\
\text { intake } \\
\text { (times/ } \\
\text { week) }\end{array}$ & $\begin{array}{l}\text { Vegetable } \\
\text { intake } \\
\text { (times/ } \\
\text { week) }\end{array}$ & $\begin{array}{l}\text { Fish } \\
\text { intake } \\
\text { (times/ } \\
\text { week) }\end{array}$ & $\begin{array}{l}\text { Sugary } \\
\text { drinks } \\
\text { (glasses/ } \\
\text { week) }\end{array}$ & $\begin{array}{l}\text { Intake of } \\
\text { sweets } \\
\text { (times/ } \\
\text { week) }\end{array}$ & $\begin{array}{l}\text { Intake of } \\
\text { fast food } \\
\text { (times/ } \\
\text { week) }\end{array}$ & $\begin{array}{l}\text { BMI } \\
\text { mean (SD) }\end{array}$ \\
\hline \multicolumn{14}{|l|}{ Overall } \\
\hline HSES/HRAD & $50.4(15.7)$ & 56.1 & 61.4 & $38.7(44.8)$ & $42.9(48.6)^{1 I, \mathrm{III}}$ & $544.0(239.0)$ & $7.3(3.7)^{\mathrm{IV}}$ & $7.3(3.7)^{\mathrm{IV}}$ & $1.3(0.0)^{\mathrm{lV}}$ & $3.5(0.1)$ & $3.7(3.7)$ & $0.6(0.0)$ & $24.9(3.7)^{\| 1, I V}$ \\
\hline LSES/HRAD & $49.0(16.3)$ & 54.6 & 47.7 & $39.5(46.0)^{\mathrm{IV}}$ & $48.8(46.0)^{1, \mathrm{III}, \mathrm{IV}}$ & 537.7 (226.4) & $6.8(3.5)^{111}$ & $6.9(3.5)^{11 I}$ & $1.3(0.0)$ & $3.7(0.1)$ & $3.4(3.5)$ & $0.7(0.0)^{111}$ & $25.7(3.5)^{1,1111}$ \\
\hline HSES/LRAD & $55.9(16.4)$ & 54.5 & 61.8 & $38.1(45.9)$ & $36.1(49.7)^{1, \mathrm{II}, \mathrm{IV}}$ & $538.0(240.9)$ & $7.4(3.8)^{I I, I V}$ & $7.3(3.8)^{I I, I V}$ & $1.2(0.0)^{\mathrm{IV}}$ & $3.5(0.1)$ & $3.5(3.8)$ & $0.6(0.0)^{I I}$ & $24.6(3.8)^{11, \mathrm{IV}}$ \\
\hline LSES/LRAD & $51.6(16.5)$ & 58.2 & 44.7 & $37.0(48.1)^{\prime \prime}$ & $42.7(48.1)^{\mathrm{II}, \mathrm{III}}$ & $529.3(244.4)$ & $6.7(4.0)^{1, \mathrm{III}}$ & $6.7(4.0)^{1, \mathrm{III}}$ & $1.2(0.0)^{1, \text {,II }}$ & $3.8(0.1)$ & $3.4(4.0)$ & $0.6(0.0)$ & $25.7(4.0)^{1, \mathrm{III}}$ \\
\hline Total & $51.8(16.4)$ & 56.0 & 53.6 & $38.4(46.5)$ & $42.9(47.6)$ & 536.4 (224.5) & $7.0(5.0)$ & $7.0(3.8)$ & $1.3(1.2)$ & $3.6(4.6)$ & $3.5(3.2)$ & $0.6(0.7)$ & $25.2(4.5)$ \\
\hline \multicolumn{14}{|l|}{ Belgium } \\
\hline HSES/HRAD & $55.6(15.7)$ & 54.2 & 46.7 & 36.7 (52.5) & $40.9(54.5)^{\mathrm{IV}}$ & $516.3(244.4)$ & $7.1(6.1)$ & $7.4(4.0)$ & $1.3(2.0)$ & $4.2(0.3)$ & $4.8(4.0)^{\mathrm{II}, \mathrm{IV}}$ & $0.6(0.0)$ & $25.2(4.0)^{\prime \prime}$ \\
\hline LSES/HRAD & $54.6(16.3)$ & 50.2 & 28.9 & 38.5 (52.9) & $47.4(55.0)$ & $521.8(249.8)$ & $7.0(6.3)$ & $7.0(4.2)$ & $1.2(2.1)$ & $5.1(0.3)$ & $4.0(4.2)^{1}$ & $0.6(0.0)$ & $26.0(4.2)^{1, \mathrm{III}}$ \\
\hline HSES/LRAD & $54.0(17.1)$ & 52.0 & 50.2 & $35.6(50.5)$ & $41.4(52.6)^{\mathrm{IV}}$ & $526.4(239.7)$ & $6.9(4.2)$ & $7.4(4.2)$ & $1.2(2.1)$ & $4.4(0.3)$ & $4.4(4.2)$ & $0.6(0.0)$ & $24.9(4.2)^{11}$ \\
\hline LSES/LRAD & $47.0(16.4)$ & 54.4 & 57.5 & $38.4(51.5)$ & $56.4(53.7)^{1, \mathrm{III}}$ & $504.0(244.8)$ & $6.7(6.4)$ & $7.5(4.3)$ & $1.2(2.1)$ & $4.1(0.3)$ & $4.2(4.3)^{\prime}$ & $0.6(0.0)$ & $25.3(4.3)$ \\
\hline Total BE & $53.0(16.7)$ & 53.0 & 45.7 & $37.7(50.4)$ & $47.6(52.6)$ & $517.2(221.6)$ & $6.9(5.1)$ & $7.3(3.2)$ & $1.2(1.0)$ & $4.4(5.3)$ & $4.3(3.5)$ & $0.6(0.7)$ & $25.4(4.5)$ \\
\hline \multicolumn{14}{|l|}{ France } \\
\hline HSES/HRAD & $47.6(14.8)$ & 57.5 & 73.8 & $32.0(41.1)$ & $35.9(37.9)^{\mathrm{IV}}$ & $461.5(213.5)^{\mathrm{IV}}$ & $8.0(6.3)$ & $7.7(4.7)$ & $1.6(1.6)$ & $3.3(0.3)^{\mathrm{IV}}$ & $3.5(3.2)$ & $0.6(1.6)$ & $24.5(4.7)^{\mathrm{IV}}$ \\
\hline LSES/HRAD & $46.1(14.0)$ & 58.5 & 67.5 & $33.3(40.0)$ & $38.0(37.4)^{\mathrm{III}, \mathrm{IV}}$ & $428.0(213.5)^{\mathrm{IIIIV}}$ & $7.6(5.3)$ & $7.9(5.3)^{111}$ & $1.6(1.3)$ & $4.1(0.3)$ & $3.5(4.0)$ & $0.7(1.3)$ & $24.1(4.0)^{\mathrm{IV}}$ \\
\hline HSES/LRAD & $56.1(15.6)$ & 55.1 & 80.5 & $33.5(40.4)$ & $27.0(37.4)^{\mathrm{III}}$ & $494.9(220.0)^{11, I V}$ & $8.3(6.0)$ & $8.6(4.5)^{I I}$ & $1.7(1.5)$ & $3.9(0.3)$ & $3.1(4.5)$ & $0.6(1.5)$ & $23.8(4.5)^{\mathrm{IV}}$ \\
\hline LSES/LRAD & $48.5(16.7)$ & 62.8 & 24.6 & $31.5(40.7)$ & $18.7(37.0)^{1, \text {,II }}$ & $353.0(203.4)^{1,1, I, I I I}$ & $7.2(6.2)$ & $7.0(4.9)$ & $1.4(1.2)$ & $4.6(0.3)^{\prime}$ & $3.6(3.7)$ & $0.8(1.2)$ & $25.9(4.9)^{1,11, \mathrm{III}}$ \\
\hline Total FR & $49.7(15.8)$ & 58.5 & 64.7 & $32.8(39.3)$ & $31.1(37.3)$ & $441.6(209.1)$ & $7.8(5.6)$ & $7.8(4.6)$ & $1.6(1.3)$ & $3.9(4.2)$ & $3.4(3.4)$ & $0.6(0.7)$ & $24.5(4.4)$ \\
\hline \multicolumn{14}{|l|}{ Hungary } \\
\hline HSES/HRAD & $50.4(17.1)$ & 59.0 & 71.0 & $50.8(49.5)^{\mathrm{IV}}$ & $34.8(40.6)$ & $555.9(227.1)$ & $6.7(3.8)^{\mathrm{IV}}$ & $6.5(3.8)^{I I, I V}$ & $0.9(1.3)^{\mathrm{II}, \mathrm{IV}}$ & $2.6(0.3)$ & $3.7(2.5)$ & $0.7(0.0)$ & $24.2(5.1)^{11, \mathrm{III}, \mathrm{IV}}$ \\
\hline LSES/HRAD & $48.8(15.7)$ & 60.7 & 40.2 & $42.4(48.6)^{\mathrm{IV}}$ & $40.5(40.5)^{\mathrm{III}, \mathrm{IV}}$ & 526.5 (226.6) & $5.7(4.9)$ & $5.4(3.2)^{1}$ & $0.7(0.0)^{\prime}$ & $2.7(0.3)$ & $3.5(3.2)$ & $0.6(0.0)$ & $26.6(4.9)^{1}$ \\
\hline HSES/LRAD & $48.9(16.0)$ & 65.8 & 57.5 & $40.7(49.1)$ & $28.0(39.6)^{I I}$ & $529.6(223.7)$ & $5.9(4.1)$ & $5.7(4.1)$ & $0.7(1.4)$ & $2.2(0.3)$ & $3.4(2.7)$ & $0.6(0.0)$ & $25.9(5.5)^{\prime}$ \\
\hline LSES/LRAD & 46.8 (13.3) & 66.3 & 40.0 & $33.9(49.7)^{1,11}$ & $25.0(40.1)^{11}$ & $520.5(230.8)$ & $5.3(4.8)^{1}$ & $5.0(3.2)^{1}$ & $0.6(0.0)^{1}$ & $2.8(0.3)$ & $3.0(3.2)$ & $0.6(0.0)$ & $26.7(4.8)^{\prime}$ \\
\hline Total HU & $48.5(15.4)$ & 63.1 & 49.6 & $41.0(48.5)$ & $32.1(39.8)$ & $530.4(222.0)$ & $5.8(4.4)$ & $5.6(3.8)$ & $0.7(0.7)$ & $2.6(4.3)$ & $3.4(3.0)$ & $0.6(0.5)$ & $26.0(5.1)$ \\
\hline \multicolumn{14}{|l|}{ The Netherlands } \\
\hline HSES/HRAD & $49.5(14.4)$ & 56.9 & 57.0 & 38.9 (46.3) & $52.8(50.3)^{\mathrm{II}}$ & 564.6 (227.4) & $6.8(4.0)$ & $6.2(2.0)^{\mathrm{III}}$ & $1.1(2.0)$ & $3.3(0.2)$ & $3.3(4.0)$ & $0.6(0.0)$ & $25.1(4.0)^{\mathrm{III}}$ \\
\hline LSES/HRAD & $48.7(15.6)$ & 54.1 & 52.6 & $42.2(46.1)$ & $63.8(49.7)^{1, \mathrm{IIIIIV}}$ & 571.0 (223.6) & $6.2(3.5)^{\mathrm{III}}$ & $6.4(1.8)$ & $1.2(1.8)$ & $3.2(0.2)$ & $2.8(3.5)^{I I I, I V}$ & $0.6(0.0)$ & $25.4(3.5)^{\mathrm{III}}$ \\
\hline HSES/LRAD & $60.6(14.9)$ & 50.0 & 71.0 & $42.6(47.6)$ & $43.3(51.4)^{1, \mathrm{II}}$ & $557.4(230.5)$ & $7.2(3.8)^{I I}$ & $6.6(1.9)^{1, \mathrm{IV}}$ & $1.2(1.9)$ & $3.1(0.2)$ & $3.5(3.8)^{11}$ & $0.5(0.0)$ & $24.0(3.8)^{1, \mathrm{IIIV}}$ \\
\hline LSES/LRAD & $59.0(15.2)$ & 54.5 & 47.4 & 39.7 (47.7) & $51.4(52.2)^{11}$ & $580.1(238.3)$ & $6.7(4.5)$ & $6.1(2.3)^{I I I}$ & $1.2(0.0)$ & $3.8(0.2)$ & $3.4(2.3)^{I I}$ & $0.6(0.0)$ & $25.2(4.5)^{111}$ \\
\hline Total NL & $54.9(15.9)$ & 54.0 & 56.4 & $40.7(45.4)$ & $52.5(49.4)$ & $568.6(211.4)$ & $6.8(3.8)$ & $6.3(1.8)$ & $1.2(1.0)$ & $3.4(4.2)$ & $3.3(2.8)$ & $0.6(0.4)$ & 25.0 (3.9) \\
\hline \multicolumn{14}{|l|}{ UK } \\
\hline HSES/HRAD & $44.5(15.1)$ & 53.8 & 82.2 & $43.0(45.8)$ & $43.7(45.8)$ & $637.5(245.8)$ & $8.6(6.5)$ & $9.7(6.5)^{\mathrm{IV}}$ & $2.1(1.3)$ & $3.3(0.3)$ & $2.2(2.6)$ & $0.8(1.3)$ & $24.6(5.2)^{\mathrm{IV}}$ \\
\hline LSES/HRAD & $39.7(15.1)$ & 53.7 & 74.6 & $38.8(46.9)$ & $47.5(46.9)^{\prime I I I}$ & $619.7(261.5)$ & $8.1(7.1)$ & $8.6(5.7)$ & $2.0(1.4)$ & $3.0(0.3)$ & $2.7(2.8)$ & $0.9(1.4)$ & $24.7(5.7)^{\mathrm{IV}}$ \\
\hline HSES/LRAD & $57.6(16.1)$ & 56.4 & 55.5 & $38.6(47.1)$ & $31.6(47.1)^{\mathrm{II}}$ & $594.8(262.5)$ & $8.6(6.3)$ & $8.3(6.3)$ & $1.9(1.6)$ & $3.0(0.3)$ & $2.3(3.1)$ & $0.7(1.6)$ & $24.7(4.7)^{\mathrm{IV}}$ \\
\hline LSES/LRAD & $51.9(16.6)$ & 62.2 & 31.7 & $34.6(46.0)$ & $30.5(46.0)$ & $640.2(252.2)$ & $8.0(5.9)$ & $8.0(5.9)^{1}$ & $1.7(1.5)$ & $3.3(0.3)$ & $2.2(3.0)$ & $0.9(1.5)$ & $26.4(5.9)^{1,1,1, I I I}$ \\
\hline Total UK & $49.1(17.2)$ & 56.4 & 59.0 & 38.7 (43.9) & 37.9 (43.9) & $619.9(230.6)$ & $8.3(6.0)$ & $8.5(5.5)$ & $1.9(1.5)$ & $3.1(3.7)$ & $2.4(2.7)$ & $0.8(1.1)$ & $25.1(4.8)$ \\
\hline
\end{tabular}




\section{DISCUSSION}

This study describes the SPOTLIGHT neighbourhood sampling strategy and survey design and explores the differences in adult obesity-related behaviours and BMI according to neighbourhood SES and RAD, across and within urban areas in five European countries. Using GIS-based tools, four urban neighbourhood types were defined in a $2 \times 2$ grid combining low/high neighbourhood SES and low/high RAD.

The results indicate that neighbourhood SES was a more dominant neighbourhood factor than RAD with regard to lifestyle behaviours and BMI. The results confirm previous findings with regard to behaviours of residents from low-SES neighbourhoods: they generally engaged in more obesity-related behaviours and reported higher BMI levels. ${ }^{8} 10{ }^{30}$ In accordance with previous literature, ${ }^{15}$ low-RAD residents were less physically active during leisure time and for transport, although this was not consistent across all countries. Belgian participants from low-SES/low-RAD neighbourhoods were found to be more physically active for transport relative to other neighbourhood types. The individual-level and contextual-level features specific to these neighbourhoods should be further evaluated (eg, focusing on aspects such as perceived safety, walking and cycling infrastructures etc). Active transport was found to be highest in the Netherlands. ${ }^{31}$ Leisure time physical activity was also relatively high in the Netherlands-but highest in Hungary. The latter was especially due to the leisure time physical activity levels of high-SES/ high-RAD inhabitants. Fish intake was found to be highest in France and the UK. This larger intake relative to other European countries has been shown before. ${ }^{32}$ The weekly intake of sugary drinks was highest in Belgium and lowest in Hungary. Current evidence from adult population-based studies across Europe is lacking with regard to soft drink intake, which hinders comparison.

BMI differences by RAD were inconsistent across countries: inhabitants of high-RAD neighbourhoods reported lower BMI than those in low RAD neighbourhoods in France, Hungary and the UK, but slightly higher BMI in Belgium and the Netherlands.

A strength of this study is the use of a similar approach for defining neighbourhood SES and RAD across all participating countries, enabling harmonised study site selection. Although SES is a multidimensional concept that can be operationalised using different indicators (ie, education, income and/or occupation), we selected household income as the SES indicator since it provided the most easily harmonised cross-country data at the lowest administrative level. We were also able to extract harmonised data on urban RAD in all five study areas. The Urban Atlas provided appropriate Europe-wide GIS data with uniform standards for all countries, thus allowing comparison of land use patterns in a range of European cities. Another strength is the large sample size from geographic and socioeconomic heterogeneous areas, and the representation of both high-SES and low-SES groups.

A limitation of this study is that the outcomes (such as obesity-related behaviours and BMI) were self-reported, which may be prone to under-reporting or overreporting. A second limitation is low response rates, ranging from $5.9 \%$ (low SES/high RAD in the UK) to $18.7 \%$ (high SES/low RAD in Belgium). As expected, we received lower response rates in low-SES neighbourhoods as compared to high-SES neighbourhoods. Although these percentages are common in large surveys among the general population, generalisation of outcomes should be done with caution as selection bias may have occurred.

The sampling strategy and survey results yield several insights for public health researchers and policymakers in the European context. The sampling process was performed using free publicly available GIS data sources and enables further linkage to specific obesity-related behavioural characteristics of environments, for example, using free publicly available remote imaging. ${ }^{33} 34$

The survey results show that adults' health behaviours and BMI differ across countries and type of neighbourhood. Neighbourhood SES differences were found to be most prominent with regard to the studied outcomes, whereas RAD seemed to be related specifically to physical activity behaviours. Further studies should provide insight into the pathways that link these environmental elements to individual characteristics.

\section{Author affiliations}

${ }^{1}$ Department of Epidemiology \& Biostatistics and the EMGO Institute for Health and Care Research, VU University Medical Center, Amsterdam, The Netherlands

${ }^{2}$ Equipe de Recherche en Epidémiologie Nutritionnelle (EREN), Université Paris 13, Centre de Recherche en Epidémiologie et Statistiques, Inserm (U1153), Inra (U1125), Cnam, COMUE Sorbonne Paris Cité, Bobigny, France ${ }^{3}$ Paris Est University, Lab-Urba, UPEC, Urban Institut of Paris, Créteil, France ${ }^{4}$ Department of Movement and Sports Sciences, Faculty of Medicine and Health Sciences, Ghent University, Ghent, Belgium

${ }^{5}$ ECOHOST-The Centre for Health and Social Change, London School of Hygiene and Tropical Medicine, London, UK

${ }^{6}$ Department of Preventive Medicine, Faculty of Public Health, University of Debrecen, Debrecen, Hungary

${ }^{7}$ Department of Nutrition Pitié-Salpêtrière Hospital (AP-HP), Université Pierre et Marie Curie-Paris 6, Centre for Research on Human Nutrition Ile-de-France (CRNH IdF), Institute of Cardiometabolism and Nutrition (ICAN), Paris, France

Contributors JL, MBR, JDM, HC, SC, KG, HB, HR, IDB, JB and J-MO were involved in the development of the survey questionnaire and participated in the data collection. MBR did the neighbourhood sampling, supervised by $\mathrm{HC}$ and J-MO. JL did the analyses. JL and MBR drafted the first version of the manuscript. JDM, HC, SC, KG, HB, HR, IDB, JB and J-MO provided direct input into the interpretation of results and revised, edited and decided on the final content of the manuscript.

Funding This work is part of the SPOTLIGHT project (http://www. spotlightproject.eu) funded by the Seventh Framework Programme (CORDIS FP7) of the European Commission, HEALTH (FP7-HEALTH-2011-two-stage), Grant agreement No. 278186. The content of this article reflects only the authors' views and the European Commission is not liable for any use that may be made of the information contained therein.

Competing interests None declared. 
Ethics approval The study protocol was approved by the corresponding local ethics committees of each participating research centre.

Provenance and peer review Not commissioned; externally peer reviewed.

Data sharing statement No additional data are available.

Open Access This is an Open Access article distributed in accordance with the Creative Commons Attribution Non Commercial (CC BY-NC 4.0) license, which permits others to distribute, remix, adapt, build upon this work noncommercially, and license their derivative works on different terms, provided the original work is properly cited and the use is non-commercial. See: http:// creativecommons.org/licenses/by-nc/4.0/

\section{REFERENCES}

1. Fisher E, Fitzgibbon M, Glasgow R, et al. Behavior matters. Am J Prev Med 2011;40:e15-30.

2. World Health Organization. Impact of obesity on health. In: Branca F, Nikogosian $\mathrm{H}$, Lobstein $\mathrm{T}$, eds. The challenge of obesity in the European Region and the strategies for response. Copenhagen: World Health Organizational Regional Office for Europe, 2007:20-7.

3. Beaglehole R, Bonita R, Alleyne G, et al. UN high-level meeting on non-communicable diseases: addressing four questions. Lancet 2011;378:449-55.

4. Egger G, Swinburn B. An 'ecological' approach to the obesity pandemic. BMJ 1997;315:477-80.

5. Sallis J, Floyd M, Rodriguez D, et al. Role of built environments in physical activity, obesity, and cardiovascular disease. Circulation 2012;125:729-37.

6. Mackenbach JD, Rutter $\mathrm{H}$, Compernolle $\mathrm{S}$, et al. Obesogenic environments: a systematic review of the association between the physical environment and adult weight status, the SPOTLIGHT project. BMC Public Health 2014;14:233.

7. Brug J. Determinants of healthy eating: motivation, abilities and environmental opportunities. Fam Pract 2008;25:150-5

8. Boone-Heinonen J, Gordon-Larsen P, Kiefe Cl, et al. Fast food restaurants and food stores: longitudinal associations with diet in young to middle-aged adults: the CARDIA study. Arch Intern Med 2011;171:1162-70.

9. Swinburn B, Egger G, Raza F. Dissecting obesogenic environments: the development and application of a framework for identifying and prioritizing environmental interventions for obesity. Prev Med 1999;29:563-70.

10. Drewnowski A, Rehm CD, Arterburn D. The geographic distribution of obesity by census tract among 59767 insured adults in King County, WA. Int J Obes (Lond) 2014;38:833-9.

11. Ferdinand A, Sen B, Rahurkar S, et al. The relationship between built environments and physical activity: a systematic review. $A m \mathrm{~J}$ Public Health 2012;102:e7-13.

12. Feng J, Glass TA, Curriero FC, et al. The built environment and obesity: a systematic review of the epidemiologic evidence. Health Place 2010;16:175-90.

13. Ding D, Gebel K. Built environment, physical activity, and obesity: what have we learned from reviewing the literature? Health Place 2012;18:100-5.

14. Durand CP, Andalib M, Dunton GF, et al. A systematic review of built environment factors related to physical activity and obesity risk: implications for smart growth urban planning. Obes Rev 2011;12: e173-82.
15. Berrigan D, Tatalovich Z, Pickle LW, et al. Urban sprawl, obesity, and cancer mortality in the United States: cross-sectional analysis and methodological challenges. Int J Health Geogr 2014;13:3.

16. Lakerveld J, Brug J, Bot S, et al. Sustainable prevention of obesity through integrated strategies: the SPOTLIGHT project's conceptual framework and design. BMC Public Health 2012;12:793.

17. European Environment Agency. Towards an Urban Atlas: Assessment of spatial data on 25 European cities and urban areas. Environmental Issue Report No 30. 2002.

18. Urban Atlas: accessible through http://www.eea.europa.eu/ data-and-maps/data/urban-atlas

19. Demarest S, Van Der Heyden J, Charafeddine R, et al. Socio-economic differences in participation of households in a Belgian national health survey. Eur J Public Health. 2013;23:981-5.

20. Dillman DA. Mail and internet surveys: the tailored design Method. New York: John Wiley and Sons, 2000.

21. Craig CL, Marshall AL, Sjöström M, et al. International physical activity questionnaire: $12-$ Country reliability and validity. Med Sci Sports Exerc 2003;35:1381-95.

22. Marshall AL, Miller YD, Burton NW, et al. Measuring total and domain-specific sitting: a study of reliability and validity. Med Sci Sports Exerc 2010;42:1094-102.

23. Frank L, Sallis J, Conway T, et al. Many pathways from land use to health. J Am Plan Assoc 2006;72:75-87.

24. Kearney JM, McElhone S. Perceived barriers in trying to eat healthier-results of a pan-EU consumer attitudinal survey. $\mathrm{Br} J \mathrm{Nutr}$ 1999;81(Suppl 2):S133-7.

25. Spittaels H, Foster C, Oppert JM, et al. Assessment of environmental correlates of physical activity: development of a European questionnaire. Int J Behav Nutr Phys Act 2009;6:39.

26. Curl CL, Beresford SAA, Hajat A, et al. Associations of organic produce consumption with socioeconomic status and the local food environment: Multi-Ethnic Study of Atherosclerosis (MESA). PLoS ONE 2013;8:e69778.

27. Beenackers MA, Kamphuis CBM, Mackenbach JP, et al. Why some walk and others don't: exploring interactions of perceived safety and social neighborhood factors with psychosocial cognitions. Health Educ Res 2013;28:220-33.

28. Sousa VD, Rojjanasrirat W. Translation, adaptation and validation of instruments or scales for use in cross-cultural health care research: a clear and user-friendly guideline. J Eval Clin Pract 2011;17:268-74.

29. De Vet HCW, Terwee CB, Mokkink LB, et al. Measurement in medicine: a practical guide. Cambridge University Press, 2011.

30. Sobal J, Stunkard AJ. Socioeconomic status and obesity: a review of the literature. Psychol Bull 1989;105:260-75.

31. Pucher J, Buehler R. Making cycling irresistible: lessons from the Netherlands, Denmark and Germany. Transport Rev 2008;28:495-528

32. Welch AA, Lund E, Amiano $\mathrm{P}$, et al. Variability of fish consumption within the 10 European countries participating in the European Investigation into Cancer and Nutrition (EPIC) study. Public Health Nutr 2002;5:1273-85.

33. Bethlehem J, Mackenbach J, Ben-Rebah M, et al. The SPOTLIGHT virtual audit tool: a valid and reliable tool to assess obesogenic characteristics of the built environment. Int $J$ Health Geogr 2014;13:52.

34. Charreire $H$, Mackenbach JD, Ouasti $M$, et al. Using remote sensing to define environmental characteristics related to physical activity and dietary behaviours: a systematic review (the SPOTLIGHT project). Health Place 2014;25:1-9. 